GUIDE TO NUMERICAL ANALYSIS 
Consultant Editor: David A. Towers,

Senior Lecturer in Mathematics,

University of Lancaster

The Titles in this Series:
Abstract Algebra
Linear Algebra
Numerical Analysis

Further titles are in preparation. 


\title{
Guide to Numerical Analysis
}

\author{
Peter R. Turner
}

Department of Mathematics

University of Lancaster

Lancaster, UK
Mathematics Department

and United States Naval Academy

Annapolis, MD 21402, USA 
All rights reserved. No reproduction, copy or transmission of this publication may be made without written permission.

No paragraph of this publication may be reproduced, copied or transmitted save with written permission or in accordance with the provisions of the Copyright Act 1956 (as amended), or under the terms of any licence permitting limited copying issued by the Copyright Licensing Agency, 33-4 Alfred Place, London WC1E 7DP.

Any person who does any unauthorised act in relation to this publication may be liable to criminal prosecution and civil claims for damages.

First published 1989

Published by

MACMILLAN EDUCATION LTD

Houndmills, Basingstoke, Hampshire RG21 2XS

and London

Companies and representatives

throughout the world

British Library Cataloguing in Publication Data

Turner, Peter

Guide to numerical analysis

1. Numerical analysis. Computation

1. Title

519.4

ISBN 978-0-333-44947-9

ISBN 978-1-349-09784-5 (eBook)

DOI 10.1007/978-1-349-09784-5

To my wife, Pat, for her

patience and encouragement throughout 


\section{CONTENTS}

Editor's foreword

vii

Preface

ix

1 NUMBER REPRESENTATIONS AND ERRORS 1

1.1 Introduction 1

1.2 Floating-point numbers $\quad 2$

1.3 Sources of errors 6

1.4 Measures of error and precision 9

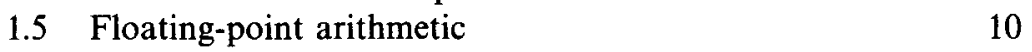

2 ITERATIVE SOLUTION OF EQUATIONS;

CONVERGENCE OF SEQUENCES 15

2.1 Introduction 15

2.2 The method of bisection 16

$\begin{array}{lll}2.3 & \text { Simple iteration } & 21\end{array}$

2.4 Newton's method 26

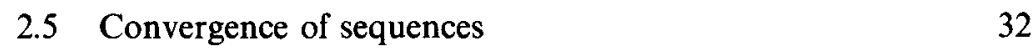

2.6 Convergence of iterative sequences 43

3 SERIES APPROXIMATION OF FUNCTIONS; CONVERGENCE OF SERIES

3.1 Introduction 51

3.2 Convergence of series 53

3.3 Series of positive terms 57

3.4 Series of mixed sign; absolute convergence 62

3.5 Convergence of power series 67

3.6 Series solution of differential equations $\quad 71$ 
4 INTERPOLATION AND APPROXIMATE

EVALUATION OF FUNCTIONS

4.1 Introduction 77

4.2 Lagrange interpolation $\quad 80$

4.3 Difference representations $\quad 85$

$\begin{array}{llr}4.4 & \text { Splines } & 96\end{array}$

4.5 CORDIC algorithms 105

5 NUMERICAL CALCULUS

5.1 Introduction 115

5.2 Numerical integration 115

$\begin{array}{lll}5.3 & \text { Practical numerical integration } & 128\end{array}$

5.4 Numerical differentiation 137

5.5 Maxima and minima 141

6 DIFFERENTIAL EQUATIONS 149

$\begin{array}{lll}6.1 \text { Introduction } & 149\end{array}$

6.2 Runge-Kutta methods 151

6.3 Multistep methods 156

6.4 Systems of differential equations $\quad 161$

6.5 Shooting methods 163

7 LINEAR EQUATIONS 166

$\begin{array}{lll}7.1 & \text { Introduction } & 166\end{array}$

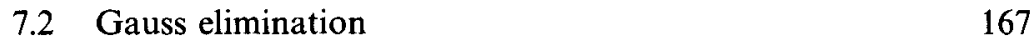

7.3 LU factorisation; iterative refinement 173

$\begin{array}{lll}7.4 & \text { Iterative methods } & 178\end{array}$

$\begin{array}{ll}7.5 & \text { Linear least-squares approximation } \\ & 182\end{array}$

$\begin{array}{ll}\text { References and further reading } & 190\end{array}$

Answers and solutions to selected exercises 192

$\begin{array}{ll}\text { Index } & 207\end{array}$ 


\section{EDITOR'S FOREWORD}

Wide concern has been expressed in tertiary education about the difficulties experienced by students during their first year of an undergraduate course containing a substantial component of mathematics. These difficulties have a number of underlying causes, including the change of emphasis from an algorithmic approach at school to a more rigorous and abstract approach in undergraduate studies, the greater expectation of independent study, and the increased pace at which material is presented. The books in this series are intended to be sensitive to these problems.

Each book is a carefully selected, short, introductory text on a key area of the first-year syllabus; the areas are complementary and largely selfcontained. Throughout, the pace of development is gentle, sympathetic and carefully motivated. Clear and detailed explanations are provided, and important concepts and results are stressed.

As mathematics is a practical subject which is best learned by doing it, rather than watching or reading about someone else doing it, a particular effort has been made to include a plentiful supply of worked examples, together with appropriate exercises, ranging in difficulty from the straightforward to the challenging.

When one goes fellwalking, the most breathtaking views require some expenditure of effort in order to gain access to them: nevertheless, the peak is more likely to be reached if a gentle and interesting route is chosen. The mathematical peaks attainable in these books are every bit as exhilarating, the paths are as gentle as we could find, and the interest and expectation are maintained throughout to prevent the spirits from flagging on the journey. 


\section{PREFACE}

This book has been developed from course notes for a variety of introductory courses in numerical methods and analysis which I have taught at the University of Lancaster and the University of Maryland. The level and content of these courses have varied considerably but have included all the material covered here. The intention of this book is to provide a gentle and sympathetic introduction to many of the basic problems of scientific computing and the wide variety of methods used for their solution. The book is therefore suitable as a first course in numerical mathematics or computation for first-year undergraduates - whether they are intending mathematicians or users of mathematics such as engineers, scientists or economists.

This, of course, precludes the possibility of providing a fully rigorous treatment of all the most up-to-date algorithms and their analyses. The intention is rather to give an appreciation of the need for numerical methods for the solution of different types of problem and to discuss the basic approaches. For each of the problems, this is followed by at least some mathematical justification and, most importantly, examples to provide both practical justification of the methods and motivation for the reader. The level of mathematical justification is determined largely by the desire to keep the assumed prerequisite mathematical knowledge to a minimum. Thus, for example, no knowledge of linear algebra is assumed beyond the most basic matrix algebra and analytic results are based only on a sound knowledge of A-level calculus and the ability to apply the intermediate-value theorem and mean-value theorem. Inevitably this means that some methods such as those for the numerical solution of differential equations are not derived in a detailed and rigorous manner. Such methods are nonetheless justified and/or derived by appealing to other techniques discussed earlier in the book such as those for numerical integration and differentiation. In contrast, in situations where rigorous explanation can be included without creating bafflement rather than enlightenment, this is given. In the chapter on iterative solution of equations, for instance, the introductory sections are followed by a brief formal treatment of convergence of sequences and then a discussion 
of the convergence of iterative schemes. The formal treatment of convergence of sequences and the later section on convergence of series could easily be omitted from a first course in numerical methods for engineering students.

The practical justification is provided by examples and exercises many of which make use of the BASIC programs which are included for several methods. The provision of such practical 'justification' necessitates the careful, even if empirical, consideration of errors and their control. Chapter 1 is devoted to floating-point arithmetic and errors and, throughout the subsequent chapters, we take time to consider the precision of our numerical solutions and how this can be safeguarded or improved.

The use of BASIC as a programming language is intended to make the book more easily accessible to students who have no background in computing. Many of the exercises will demand only minor changes to the given programs while very few require the writing of a program from scratch. BASIC serves this purpose well as it is both a highly 'readable' language especially in the fairly powerful form used here - and it is a good preparation for more advanced programming in a high-level language such as FORTRAN. It should therefore be possible for a student with virtually no prior knowledge of computing to be able to understand what is going on in the programs and to make intelligent use of them to enhance his or her understanding of the methods under discussion. The programs are not intended to be sophisticated or robust pieces of software but are simply illustrative.

The intention of the book as a whole is to provide the student with an introduction to this subject which is not in its combined demands of computing, motivation, manipulation and analysis paced such that only the most able can 'see the wood for the trees'. The major effort of programming is thus removed from the reader as are the harder parts of the analysis. The algebraic manipulation is largely unavoidable but is carefully explainedespecially in the early stages. The motivation for the numerical methods is provided by the examples - which are not all of types which can be solved directly - and the numerical methods themselves provide motivation for the necessary analysis.

Finally, I must thank two close friends for their help in getting this book 'off the ground'. David Towers, as editor of the series, has been a willing adviser and a great encouragement. Charles Clenshaw has been of invaluable help in reading the draft versions of each of the chapters and suggesting many improvements in style, presentation and mathematics. 